\title{
Çok zamanlı multispektral uydu verilerinin Marmara Gölü kıyı değişimi analizinde kullanılması
}

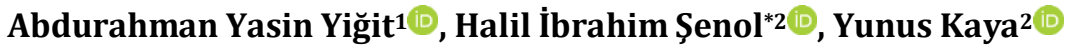 \\ ${ }_{1}^{1}$ Mersin Üniversitesi, Mühendislik Fakültesi, Harita Mühendisliği Bölümü, Mersin, Türkiye \\ 2Harran Üniversitesi, Mühendislik Fakültesi, Harita Mühendisliği Bölümü, Şanlıurfa, Türkiye
}

\author{
Anahtar Kelimeler \\ CBS \\ Uzaktan Alglama \\ Kıyı Değişiminin Saptanması \\ DSAS \\ Landsat
}

\begin{abstract}
ÖZ
Küresel ısınmaya bağlı olarak meydana gelen iklim değișikliği yağıșların ve sıcaklıkların düzensizleşmesine sebep olmaktadır. Bu nedenle sosyoekonomik açıdan küresel ölçekte büyük öneme sahip kıyı alanlarında hızlı değişimler meydana gelmektedir. Kıyı alanlarındaki uzun süreli değișimlerin izlenmesi için kullanılan yöntemlerden birisi uzaktan algılama yöntemidir. NASA ve USGS tarafından sağlanan Landsat uydu misyonu sayesinde $1970 \mathrm{li}$ yıllardan günümüze kadar düzenli multispektral veri temin edilebilmektedir. Yine NASA tarafından geliștirilen ve ArcGIS yazılımı üzerinden kullanılabilen DSAS aracı sayesinde kıyı çizgilerinin farklı tarihler arasındaki değişimleri izlenebilmekte ve değişim miktarları istatistiksel olarak analiz edilebilmektedir. Bu çalışmada Manisa ili sınırları içerisinde bulunan ve bir alüvyal set gölü olan Marmara Gölü'ne ait 1985-2020 arasındaki 5’er yıllık periyotlarda kıyı alanlarındaki değișimler incelenmiștir. 8 adet Landsat verisi üzerinden MNDWI ve nesne tabanlı sınıflandırma yöntemiyle kıyı çizgisi çıkarılmıștır. Çıkarılan kıyı çizgisi üzerinden DSAS ile erozyon ve dolgu miktarları belirlenerek istatistiksel yöntemlerle (EPR ve LRR) analiz edilmiștir. Çalıșma sonucunda $\mathrm{R}^{2}$ ve Pearson's $\mathrm{r}$ yöntemine göre EPR ve LRR arasındaki korelasyon değerleri sırasıyla \%94 ve \%97 olarak hesaplanmıștır.
\end{abstract}

\section{Using multi-temporal and multispectral satellite data for coastal change analysis in Marmara Lake}

\section{Keywords}

GIS

Remote sensing

Shoreline Change Detection

DSAS

Landsat

\begin{abstract}
Climate change due to global warming causes irregularity in precipitation and temperature. For this reason, rapid changes occur in coastal areas, which are of great socioeconomic importance on a global scale. One of the methods used to monitor long-term changes in coastal areas is the remote sensing method. Thanks to the Landsat satellite mission provided by NASA and USGS, regular multispectral data can be obtained from the 1970s to the present. Thanks to the DSAS tool, which is also developed by NASA and can be used via ArcGIS software, the changes of the coastlines between different dates can be monitored and the amount of change can be analyzed statistically. In this study, the changes in the coastal areas of Marmara Lake, which is an alluvial barrier lake within the borders of Manisa province, were examined in 5year periods between 1985 and 2020. The shoreline was drawn from 8 Landsat data using MNDWI and object-based classification method. Erosion and accretion amounts were determined by DSAS on the extracted coastline and analyzed with statistical methods (EPR and LRR). Result of the study, correlation values between EPR and LRR according to $\mathrm{R}^{2}$ and Pearson's $r$ method were calculated as $94 \%$ and $97 \%$, respectively.
\end{abstract}




\section{Giriş}

İklim değişikliği ve değişen iklimin doğal alanlara olan etkileri son yılların önemli araştırma konularından biridir. Kıyı alanlarındaki doğal değişimler; deniz seviyesinde meydana gelen değișimler, akarsuların getirdiği toprakların etkisi, tektonik etkenler, kıyı erozyonu, dalga ve kıyı akıntıların etkisiyle oluşmaktadır. İnsan etkisiyle oluşan küresel ölçekteki değişimler ile ciddiyeti her geçen gün artan bir konudur. Özellikle ekolojik dengeye önemli katkılarda bulunan doğal yapılar bu etkiye maruz kalmaktadır. Bu doğal yapılar içerdikleri doğal zenginlikler ve yaşam kaynakları ile biyolojik çeşitliliğe imkân sağlamaktadır.

Kara ve deniz arasında bir arayüz olan kıyı șeridi önemli bir yeryüzü özelliğidir (Niya ve ark., 2013) ve gelgitler, rüzgarlar, dalga hareketleri vb. faktörlerden dolayı kısa ve uzun vadede değişime uğramaktadır (Boak ve Turner, 2005; Ali ve Narayana, 2015; Beșel ve Kayıkçı, 2020). Bunun yanında insanoğlunun tarih boyunca yerleşim, barınma, ekonomi ve ulaşım amaçlı olarak daima kıyı alanlarını kullanması, bu sahalarda yapay kökenli kıyı değişimlerinin de yaşanmasına neden olmuștur (Doygun, ve ark., 2011; Döker, 2012). Dünya nüfusunun \%60'ı kıyı alanlarında yaşamaktadır (Kurt ve ark., 2010). Kıyı alanlarında yoğun nüfus ve yerleşmenin yanında, sanayi, tarım, ticaret, ekonomi ve ulaşım alanlarının olması, kıyılarda yoğun kullanım baskısının oluşmasına neden olmaktadır. Bu baskı sonucunda kıyı alanlarından yer kazanmak için dolgu çalışmaları yapılmaktadır. Bu çalıșmalar kıyı çizgisinin ve kıyı alanın değişmesine yol açarken, kıyı ekosisteminin değişmesine de neden olmaktadir.

Kıyılar su ile karanın buluştuğu doğa ve insan için öneme sahip yerlerdir (Rahman ve ark., 2022). Kiyllar, özellikle son yıllarda, tüm dünyada gelişmenin odağı haline gelmiş ve insan aktiviteleri ve doğal olaylar sonucunda sürekli değișime uğramıștır. Özellikle kumsal kıyılar, dinlenme ve eğlenme alanı olarak oldukça ilgi çekmiştir fakat bu kıyllarda meydana gelen erozyon önemli bir problem haline gelmiştir (Gormsen, 1998; Phillips ve Jones, 2006, Page ve ark., 2017). Kıyı bölgeleri; kendilerini etkileyen rüzgâr, dalga, akıntı gibi çeşitli dış etmenler ve kendilerini besleyen akarsular gibi kaynakların ve kendilerinden malzeme kaybına yol açan çeşitli faktörleri etkisi altında binlerce yll ile ifade edilebilen bir süreçte kum, çakıl, silt ve kil gibi katı madde (sediment) taşınımı açısından dinamik bir dengeye ulaşır (Glover ve Robertson, 1998; Geyer ve ark., 2004; Mahmoodi ve ark., 2020). Böylece, kıyı dengesini bozacak bir faktör etkin olmadığı sürece kıyılarda önemli ölçüde erozyon (kıyı gerilemesi) veya yı̆̆ılma (kıyı ilerlemesi) durumlarıyla karşılaşılmaz. Kıyının dinamik dengesini bozan en önemli faktörler, ya mevsimlerdeki anormal değişimler sonucu büyük firtınaların oluşması şeklindeki doğal faktörler, ya da çeşitli insan faaliyetleri sonucu meydana gelen yapay faktörlerdir. Doğal faktörlerin etkisi onlarca yillarla ifade edilebilen uzun sürelerde kendini gösterirken, yapay faktörlerin sonuçları birkaç yıl hatta birkaç aylık kısa sürelerde görülebilmektedir (Xoplaki ve ark., 2001; Kireeva ve ark., 2020). Kıyılarda meydana gelen bu değișimin belirlenmesi ve eğer bu değișimler sorun olușturuyorsa önlemlerinin alınması gereklidir. Yıllık, mevsimsel ve hatta günlük olarak gerçekleşebilen bu değişimlerin, klasik optik ölçüm yöntemleriyle ölçülmesinin oldukça zaman alıcı ve zahmetli olması nedeniyle, uydu teknolojileri tercih edilmektedir (Ali ve ark., 2016; Carr ve ark., 2017; Bevacqua ve ark., 2018).

Uzaktan algılanan uydu görüntüleri, kıyı bölgelerinin ve kıyı şeridinin konumunu izlemek için yaygın bir şekilde kullanılmaktadır. Uzaktan algılama verileri kıyı şeridi belirlenmesinde ve zamansal değişimlerinin analizinde makul bir doğruluk sağlamaktadır (Jana ve ark., 2017). 1972 yllından bu yana LANDSAT uydu verileri ücretsiz bir șekilde araştırmacılar ve kullanıcılarla paylaşılmaktadır. Kıyı şeridinin zamansal değişiminin analizi pek çok araştırmacı tarafından incelenmiştir (Nassar ve ark., 2018; Ciritci ve Turk, 2020; Velsamy ve ark., 2020; Das ve Dhorde, 2022). Literatür incelendiğinde uzun süredir yayınlanıyor olması ve ücretsiz olmasından kaynaklı Landsat ile yapılan çalışmalar yoğunluk göstermiştir (Mitra ve Sandra, 2013). Uzun zaman aralıklarında meydana gelen kıyı değişimleri pek çok çalışmaya konu olmuştur. Hossain ve ark. (2016), 1990-2015 yılları arasında Bangladeş'in küçük bir kıyı adası olan Domar Char kıyı şeridinin dinamik modelini değerlendirmek için Landsat TM ve OLI sensorlerinin uydu görüntülerini kullanmıșlardır. Ciritci ve Turk (2020), çok zamanlı uydu görüntüleri kullanılarak yapılan kıyı değişimi analizinin yanı sıra Kalman filtresi tabanlı gelecek kıyı tahmini yapmışlardır. Roy ve Mahmood (2016), 1974-2014 arasinda Bangladeș'in Sandwip Adası'nda erozyon ve kıyıda oluşan birikim durumunu belirlemek için uydu verileriyle hidrolojik veriler arasında korelasyon kurmuşlardır. Usha ve ark. (2015), Tamil Nadu (India) sahili boyunca meydana gelen değișimleri uzaktan algılama ve mekânsal analiz tekniklerine dayanarak incelemişlerdir.

Kıyı alanlarının çok zamanlı takip edilmesi; değişikliklerin tutarlı olup olmadığına karar vermemize olanak sağlamasının yanında Coğrafi Bilgi Sistemleri (CBS) ve Uzaktan Algılama yöntemlerinin birleștirilmesiyle klyı alanlarında zamana bağlı modifikasyonları incelemek mümkündür (Şentürk ve Erener, 2017). Kıyl hareketlerinin dinamiklerini değerlendirmede kullanılan ve United States Geological Survey (USGS) (Danforth ve Thieler, 1992) tarafından geliştirilen Digital Shoreline Analysis System (DSAS) oldukça başarılı bir CBS aracıdır (Nor ve ark., 2020). DSAS, kıyıya dik ölçüm kesitleri alarak kıyı şeridindeki değişimi ölçmeye dayanmaktadır (Armah, 2011; Ahmad ve Lakhan, 2012; Dewidar ve Frihy, 2010). DSAS, klyı değişimini hesaplamak için çok zamanlı verileri karşılaştırarak End Point Rate (EPR) (Sebat ve Salloum, 2018), Linear Regression Rate (LRR), Average of Rates (AoR) gibi modeller kullanmaktadır (Jonah ve ark., 2016). Kıyı şeridindeki zamansal-mekansal değişimin nitel ve nicel olarak analiz edilmesinde DSAS'ın kullanıldığı pek çok örnek vardır (Kermani, 2016; Nassar ve ark., 2019; Gracy ve ark., 2020; Ghorai ve Bhunia, 2020; Dereli ve Tercan, 2020).

Literatürdeki çalışmalar incelendiğinde uzun zamanlı değişimlerin sıklıkla çalışıldığı gözükmektedir. Ancak son yıllarda kuraklık ve insani faktörlerden dolayı uzun 
zamanlı kıyı değişimlerinin yanında yıl içinde de ciddi oranda değişimler olmaktadır.

$\mathrm{Bu}$ çalıșmada kurumakta olan önemli alüvyal göllerimizden biri olan Marmara Gölü'ndeki kıyı değișimi incelenmiştir. Kıyı alanlarındaki değişimi tespit etmede 30 m mekânsal çözünürlüğe sahip Landsat kullanılmıştır. Çalışmada MNDWI ve obje tabanlı sınıflandırma yöntemiyle kıyı alanları belirlenmiştir. Farklı yıllara ait uydu verilerinden elde edilen kıyı çizgilerinde meydana gelen değişimlerin tespiti ve analizi için DSAS aracı kullanılmıştır. Bunun için 1985-2020 yılları arasındaki Landsat uydu verileri kullanılmıștır.

\section{Materyal ve yöntem}

\section{1. Çalışma alanı}

Marmara Gölü Manisa, Türkiye'de bulunan Akdeniz tipi sı̆̆ bir göldür. Göl alanı 12 km uzunluğunda ve 6 km genişliğindedir. Marmara gölü bir alüvyal set gölüdür ve Gediz vadisinin içinde yer almaktadır. Göl ve çevresi balıkçılık ve tarım aktiviteleri nedeniyle önemlidir. Marmara Gölü ayrıca 144 kuș çeșidini içeren önemli kuș yaşam alanlarından biridir (Gül, 2008). Bölgede genel olarak Akdeniz iklimi hâkim olsa da Gediz havzasının kendine has iklim özellikleri de hissedilir (Peel ve ark., 2007). Marmara gölü 20 farklı balık türünü içermektedir (İlhan ve Sarl, 2011).

\subsection{Veri}

$\mathrm{Bu}$ çalışmada 1985-2020 yılları arasındaki kıyı değişimini izlemek için Landsat uydu verileri kullanılmıştır. Landsat uydu sistemi yeryüzündeki doğal kaynakların izlenmesi için 1972 yılında uzaya fırlatılmıștır. İkinci kuşak olarak bilinen Landsat uyduları 1982'de Landsat 4'ün firlatılması ile bașlamıștır. İkinci kuşak Landsat uydularında Thematic Mapper (TM) sensörü kullanılmıştır. Son Landsat uydusu ise (Landsat 8) 11 Şubat 2013 tarihinde fırlatılmıştır. Landsat 8 uydusunda ikinci kuşak uydularından farklı olarak Operational Land Imager (OLI) ve Thermal Infrared Sensör (TIRS) algılayıcıları kullanılmıştır. Çalışmada 1985-2020 yılları arasında 5'er yıl arayla alınan 8 adet Landsat uydu verisi kullanılmıştır. Kullanılan uydu verilerinin özellikleri Tablo 1'de verilmiştir.

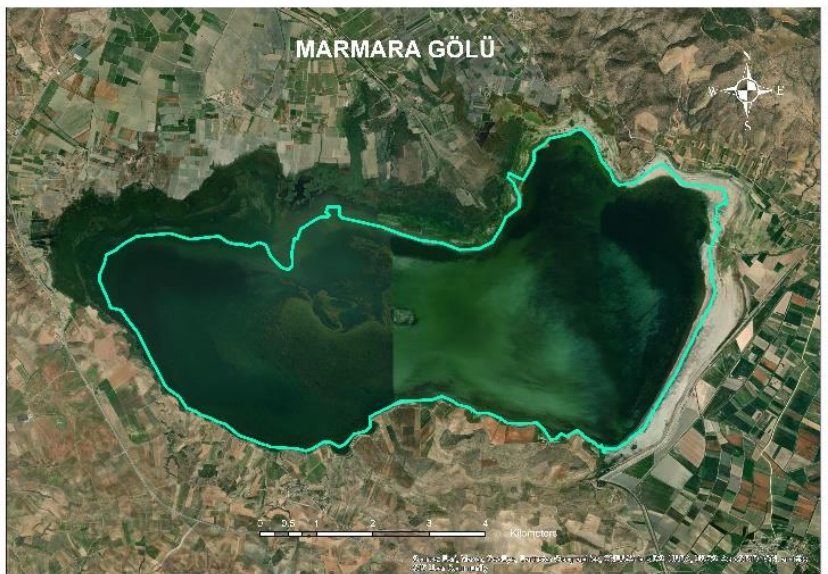

Şekil 1. Çalışma Alanı

Tablo 1. Çalıșma için Kullanılan Uydu Verilerinin Özellikleri (Spesifications of Satellite Data Used for Study)

\begin{tabular}{|c|c|c|c|c|}
\hline \multicolumn{5}{|c|}{ LANDSAT } \\
\hline Algilama Tarihi & Misyon & Yörünge & Dizi & Bulutluluk Oranı (\%) \\
\hline 30 Mayıs 1985 & Landsat 5 & 180 & 033 & 0 \\
\hline 28 Mayıs 1990 & Landsat 5 & 180 & 033 & 0 \\
\hline 26 Mayıs 1995 & Landsat 5 & 180 & 033 & 0 \\
\hline 16 Haziran 2000 & Landsat 7 & 180 & 033 & 0 \\
\hline 06 Haz. 2005 & Landsat 5 & 180 & 033 & 0 \\
\hline 03 Mayıs 2010 & Landsat 5 & 180 & 033 & 0 \\
\hline 17 Mayıs 2015 & Landsat 8 & 180 & 033 & 0 \\
\hline 20 Ağustos 2020 & Landsat 8 & 180 & 033 & 0 \\
\hline
\end{tabular}

\subsection{Yöntem}

Bu çalışmada, Marmara Gölü’nün son 35 yıllık kıyı değişimi Landsat uydu görüntüleri kullanılarak incelenmiştir. Çalışmada DSAS kullanılarak kıyı değişimine ilişkin mekansal ve zamansal değişimler istatistiksel olarak analiz edilmiş ve yorumlanmıştır.

Çalışmanın ilk aşamasından obje tabanlı sınıflandırma ile deniz ve kara alanları birbirinden ayrılmıștur. MNDWI; bitki örtüsü, toprak gürültüsü ve yerleşik alan gürültüsünü bastırıp, su alanlarını ayırt etmede başarılıdır. NDWI indeksi (Guha ve Govil, 2021) kullanıldığında genellikle su alanları ve yerleşik alanlar karıştırılır. Bu nedenle su alanları gerçekten daha fazla tahmin edilir. Bundan dolayı NDWI'ın üzerindeki yerleşik alan gürültüsünü azaltmak için yerleșik alanlarla su alanlarının birbirine karıștığı bölgelerde MNDWI önerilir. MNDWI (1) eşitliği ile hesaplanır.

$$
M N D W I=\frac{\text { Green }-S W I R}{\text { Green }+S W I R}
$$

\subsection{Kıyı çıkarımı}

Kıyı çizgisini deniz ve kara alanlarından daha iyi ayırabilmek adına MNDWI indeksi kullanılmış ve kara alanları su alanlarından çıkarılmıştır. Bu çalıșmada, Landsat verileri ile 1985-2020 yılları arasındaki 35 yıllık değişim gözlemlenmiştir. Bu doğrultuda, MNDWI indeksi kullanılarak sınıflandırılan veri poligona dönüştürülmüş ve dönüştürülen poligondan kıyı çizgileri ArcGIS yazılımı aracılığıyla çıkarılmıştır. Değişimi izlenecek kıyı çizgisi olarak özellikle son yıllarda kıyı değişiminin olduğu bilinen Marmara Gölü kıyı çizgisi seçilmiştir. Landsat ile elde edilen veri incelendiğinde kıyı çizgisinde gözle görülen bir farklılık ortaya çıkmaktadır. Bununla birlikte, 
uydu görüntülerinden elde edilen kıyı çizgileri analiz edilmiş ve hem kendi içlerindeki hem de aralarındaki uyuma da dikkat edilmiștir. Bu doğrultuda, kıyı çizgileri, ArcGIS yazılımında kullanılabilen bir araç olan ve NASA tarafından yayınlanan DSAS aracı ile analiz edilmiştir.

Kıyı çizgilerinin konum değişimlerini izlemek ve değerlendirmek için EPR ve LRR istatistiksel yaklaşımı kullanılmıştır. EPR yaklaşımı basitçe, kıyı şeritlerini ayıran mesafenin, kıyı şeritlerinin tarihleri arasındaki yıl farkına bölünmesiyle hesaplanır. EPR yaklaşımı için önerilen basit matematiksel model denklem (2) da verilmiștir (Nassar ve ark., 2019; Tercan ve Dereli, 2020).

$E P R=\frac{L_{1}-L_{2}}{t_{1}-t_{2}}$

Denklemde, $\mathrm{L}_{1}$ ve $\mathrm{L}_{2}$ kıyı çizgileri arasındaki mesafeyi ayırırken, $t_{1}$ ve $t_{2}$ ise kıyı çizgileri arasındaki zamansal farkı ortaya çıkarmaktadır.

Diğer bir matematiksel yaklaşım olan LRR yaklaşımı ise belirli bir geçiş için en küçük kareler regresyon çizgisini birden çok kıyı hattı üzerindeki çeşitli noktalara yerleştirerek oluşturulur. Tüm klyı çizgileri bu hesaplama için kullanılmaktadır. Bu analizin doğru ve tutarlı sonuçlar verebilmesi için kıyı çizgisi çıkarımlarının doğruluğu önemlidir. Çünkü bu kıyı değişikliklerinin zamansal çözünürlüğü, kıyı şeridi değişiklik oranının doğruluğu gibi, istatistiksel yöntem için önemli olan kavramları doğrudan etkiler (Nassar ve ark., 2019; Tercan ve Dereli, 2020; Ciritci ve Turk, 2019). LRR yöntemi için denklem (3) kullanılmıştır (Nassar ve ark., 2019);

$D=m t+a$

Denklemde, D başlangıç çizgisinden olan mesafeyi ifade ederken (m), t kıyı çizgisi zaman değişimlerini (yıl), $m$ yerleştirilen çizginin eğimini $(\mathrm{m} / \mathrm{yl})$, ve a ise $y$ ekseninin kesme noktasını ifade etmektedir. Lineer regresyon yönteminde örneklem veriler ortalama uzaklık değerleri ile hesaplanır ve bu değer en aza indirgenerek belirlenir.

$\mathrm{Bu}$ çalışmada, Marmara Gölü kıyı çizgisi Landsat uydu görüntüleri ile çıkarılmış ve DSAS yazılımı üzerinden kıyı çizgisi değişimleri EPR ve LRR istatistiksel yöntemlerine göre değerlendirilmiş ve aralarındaki ilişki incelenmiştir.

\section{Bulgular}

Marmara Gölü, Türkiye'nin önemli doğal yaşam ve temiz su kaynağı alanlarından biridir. Göl suyu genellikle temiz su ve tarımsal sulama amaçlı kullanılmaktadır. Bu nedenle, Marmara Gölü kıyı değişimini gözlemlemek ve oluşabilecek olumsuzluklara karşı önlem almak hayati önem taşımaktadır. Metodolojiye uygun bir biçimde DSAS ile analize sokulan kıyı çizgileri için EPR ve LRR yöntemleri ile analiz yapılmıştır. DSAS ile analiz edilmiş kıyılar için kesit değerleri üretilmiştir.

Çalışmanın amacı, bölgenin yakın zamanındaki kıyı değişimini tespit etmek ve kıyı değişimine neden olabilecek faktörleri ortaya koymaktır. Bu nedenle veri temini için, USGS tarafından yayınlanan $30 \mathrm{~m}$ çözünürlüklü Landsat verisi kullanılmıştır. Landsat verilerinden daha anlamlı sonuçlar çıkarmak için (orta çözünürlüklü veriler olduğundan) 5 yll aralıklı veri kullanılmıștır. Bölgede insan katkısıyla olușan etkilerin bașında Marmara Gölü etrafında bulunan tarım alanları ve plansız sulama vardır. Son yıllarda, plansız tarımsal sulamanın artması ve küresel iklim değișiklikleri gölün kuruyacak bir şekilde erozyona uğramasındaki en büyük etkenlerdendir.

Kıyı çizgilerindeki değişiklikleri izlemek için referans hattı oluşturmak gereklidir. Referans hattı oluşturmak için üç farklı yöntem mevcuttur. Bunlar; kıyı şeridine belirli bir mesafede olan bir çizgi oluşturmak, eski bir kıyı çizgisinin temel alınıp kullanılması ve tampon (buffer) oluşturma yöntemidir. Üçüncü yöntem, en yakın kıyı şeridiyle aynı şekle sahip olduğu için en güvenilir ve doğru yöntemdir, bu nedenle mevcut çalışmada referans hattı oluşturmak için bu yöntem kullanılmıştır (Nassar ve ark., 2019). Uydu verilerinden çıkarılan çizgilerden için de DSAS parametrelerini sağlamak için tüm kıyı çizgileri baz alınarak 50 metrelik bir tampon oluşturulmuş ve referans hattı ile ilgili spesifik parametreler öznitelik tablosuna eklenmiştir. Bununla birlikte birleștirilmiș kıyı çizgileri kıyı hattı isimli başka bir veriye eklenmiş ve DSAS aracı için gerekli olan spesifik parametreler öznitelik tablosuna eklenmiștir.

Landsat uydu görüntülerinden çıkarılan kıyı çizgileri için, 20 metre aralıklı ve klyı çizgisindeki ciddi değişimden ötürü 300 metrelik bir alanı tarayan kesitler üretilmiştir (Şekil 2 ve 3). Tüm kesitler için \%90 güven aralığından EPR ve LRR değerleri üretilmiştir. Çalışma için bölgedeki 3 farklı ve değişimin en fazla olduğu alanlar seçilmiştir.

EPR ve LRR değerleri doğrusal olarak değerlendirilmiş ve $\mathrm{R}^{2}$ değeri \%94 olarak hesaplanmıştır. Bununla birlikte kıyılar arasındaki korelasyon Pearson's r yöntemiyle de araştırılmış ve korelasyon değeri \%97 olarak hesaplanmıştır (Şekil 4).

EPR/LRR arasında grafik çizerek oluşturulan Fark Gecikme Grafiği (Şekil 5), hata terimlerinin bağımlılığını incelemek için kullanılmaktadır. Bir gecikme grafiğindeki rastgele olmayan herhangi bir desen, varyansın rastgele olmadığını gösterir. Analiz edilen veriler zaman serisi verileriyse (veriler sıralı olarak kaydedilir), Verilerin Farka Karşı grafiği, fark terimi ve zaman arasındaki korelasyonu yansitacaktır. Sifır civarında dalgalanan desenler, fark teriminin bağımlı olduğunu gösterecektir. Deneysel işlem sırasında varyans (Şekil 5) sürüklenme kontrol etmek için kullanılabilir. Farklar sıfır civarında rastgele dağılmışsa, süreçte kayma olmadığı anlamına gelir.

Sapma Histogramı, varyansın normal dağılıp dağılmadığını kontrol etmek için kullanılabilir (Şekil 6). Sıfır etrafında eşit olarak dağıtılan simetrik çan şeklindeki bir histogram, normallik varsayımının doğru olma olasılığının yüksek olduğunu gösterir. Histogram, rastgele hatanın normal dağılmadığını gösteriyorsa, modelin altında yatan varsayımların ihlal edilmiş olabileceğini gösterir. 


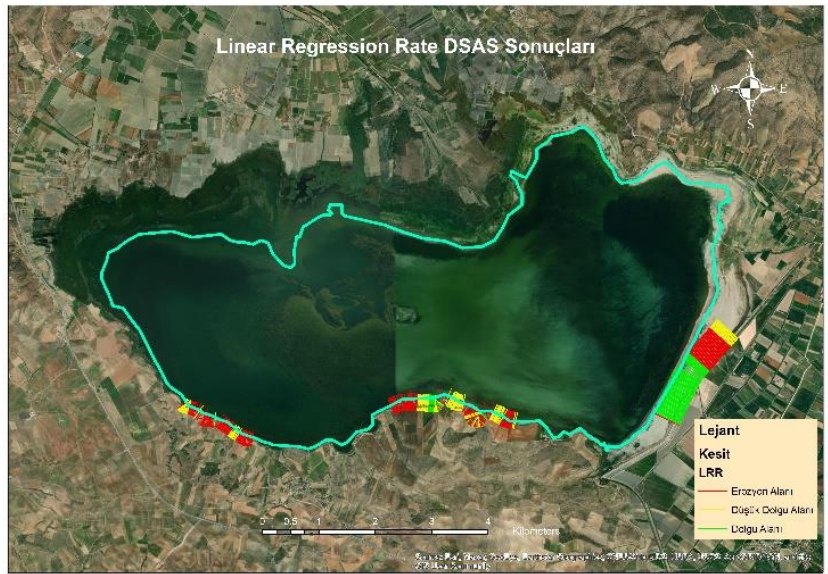

Şekil 2. LRR İstatistikleri ile Landsat Verilerine Ait DSAS Sonuçları

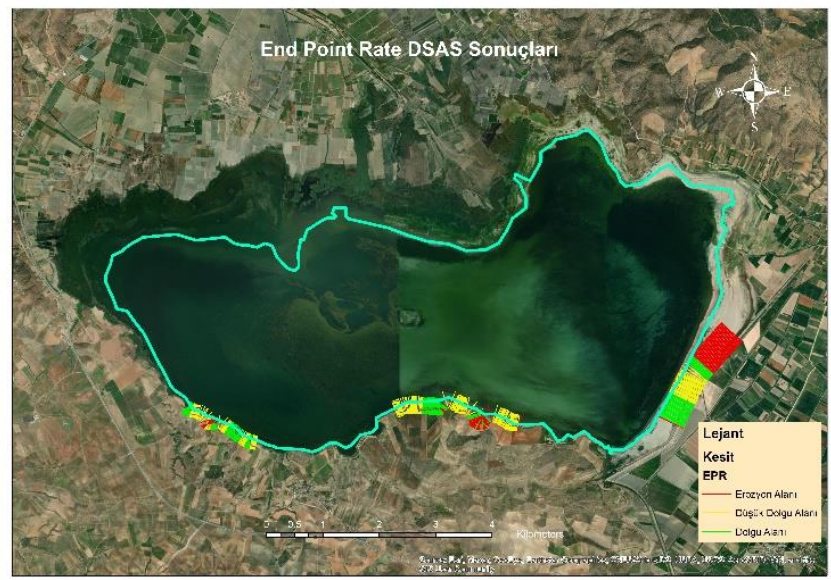

Şekil 3. EPR İstatistikleri ile Landsat Verilerine Ait DSAS Sonuçları

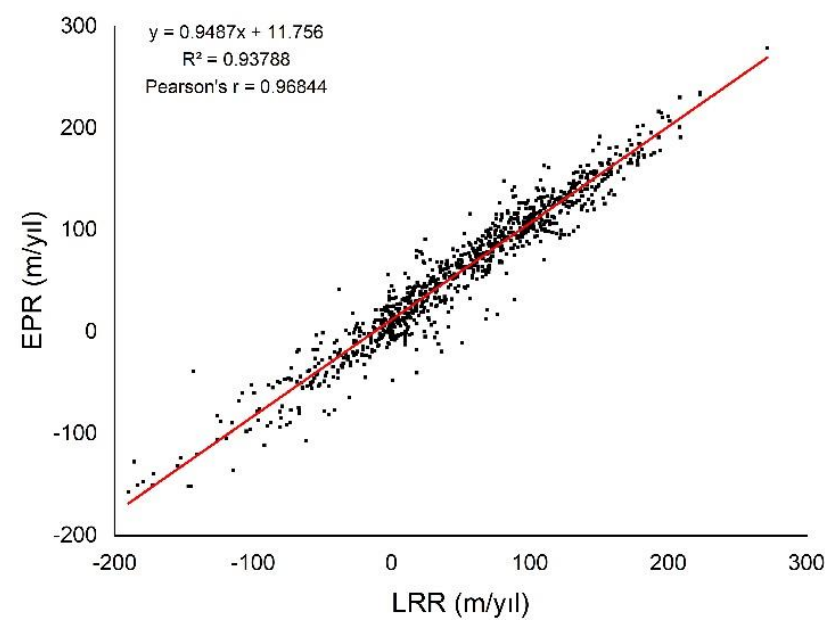

Şekil 4. $\mathrm{R}^{2}$ ve Pearson's $r$ yöntemine göre EPR ve LRR arasındaki korelasyon değerleri

Varyansın normal dağılıp dağılmadığını kontrol etmek için farkların normal bir olasılık grafiği kullanılabilir. Sonuç grafiği yaklaşık olarak doğrusal ise, hata terimlerinin normal dağıldığını varsayarak ilerlenebilir. Yüzdeliklere karşı sıralı farka dayalıdır, yüzdelikler Eşitlik (4) ile hesaplanabilir:

$\frac{\left(i-\frac{3}{8}\right)}{\left(n+\frac{1}{4}\right)}$ n , toplam veri kümesi sayısıdır ve i , fark verisidir. Artıkların normal olasılık grafiği Şekil 7'de gösterilmiştir.

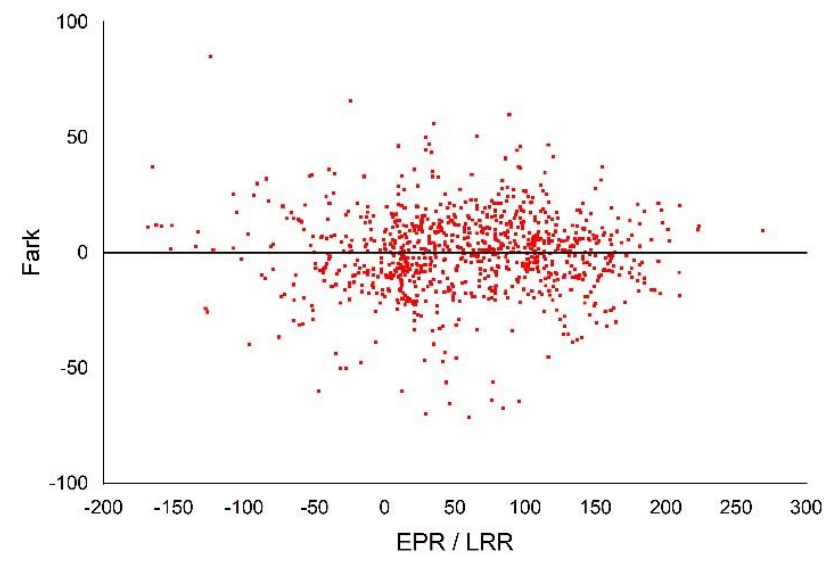

Şekil 5. ERP/LRR fark teriminin bağımsızlığının kontrol edilmesi

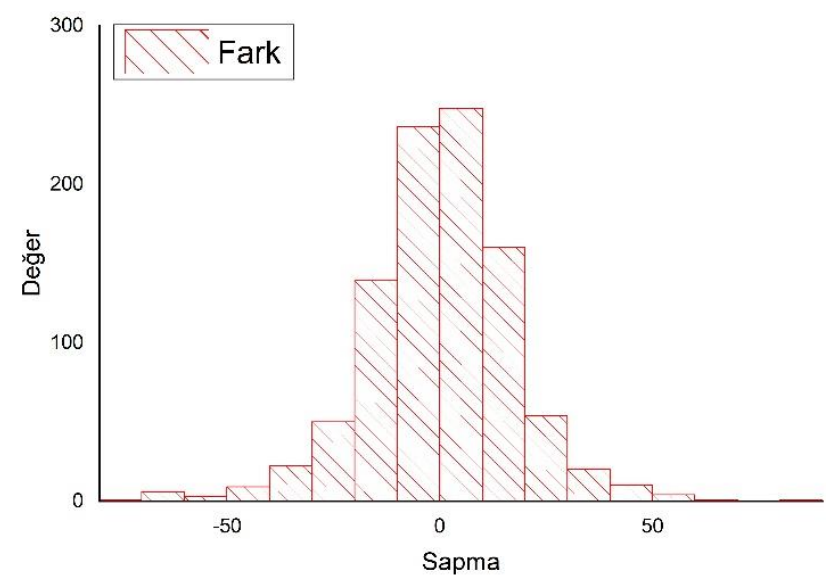

Şekil 6. Sapmanın normal olarak dağıldığını gösteren fark histogramı

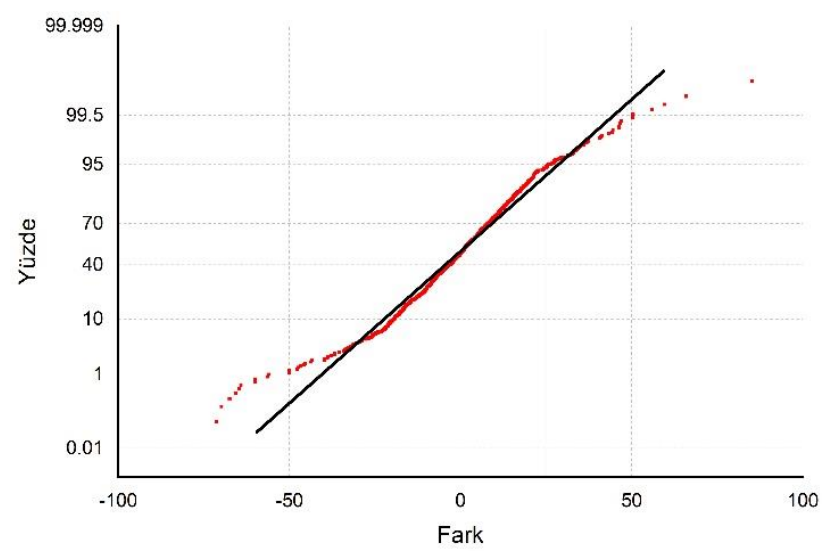

Şekil 7. Farkların Normal Olasılık Grafiği

\section{Sonuçlar}

İnsanlar tarih boyunca su ve sulama ihtiyacını karşılamak için göl ve nehir kenarlarına yerleșmișlerdir. Daha sonra gemilerin icadiyla birlikte denizler ve okyanuslar önemli hale gelmiştir. Günümüzde ise kıylar zengin doğal kaynak potansiyeli barındıran, insanlar için ekonomik kazanç firsatı sunan, gelişme potansiyeli yüksek alanlardandır. Tüm bunların yanında turizm faaliyetlerinin hızlanmasıyla birlikte kıyılar giderek daha önemli bir hale gelmiştir. Bundan dolayı kıyı alanları 
tarih boyunca insanlık için önemli olmuştur. Tüm bu avantajlarının yanında küresel ısınma kaynaklı, kıyıların ve su kaynaklarının yanlış kullanımı, deniz ve okyanusların çekilmesine, kıyı çizgisinin kısalmasına ve kıyılardaki biyolojik çeşitliliğin zarar görmesine sebep olmaktadır. İnsan faktörünün devreye girmesinden dolayı kıyı alanlarında kısa süre içerisinde ciddi değișimler meydana gelmektedir.

Bu çalışmada Türkiye için önemli su kaynaklarından biri olan Marmara Gölünün kıyı değişimi analiz edilmiştir. Uzaktan algılanan uydu verileri kullanılarak 5 yıl aralıklı kıyı değişimi analiz edilmiştir. Çalışmada 1985-2020 yılları arasında 5'er yıl arayla elde edilen 8 adet Landsat uydu verisi kullanılarak bölgenin 35 yıllık değişimi incelenmiştir. Landsat verilerinin mekânsal çözünürlüğünden dolayı yıllık değişimleri yakalayamadı̆̆ı, ancak 5 yıllık değişimlerde başarılı olduğu görülmektedir. Ancak şunu inkâr edemeyiz ki; uzun yıllardır veri temini sağlayan Landsat verileri özellikle zaman aralıklı değişimleri ortaya koymada hala önemli bir araçtır.

Analiz sonuçları incelendiğinde 35 yıllık değişimlerde 1.5 km'ye kadar erozyon görülmüştür. Özellikle zaman içerisinde önemli su kaynaklarından olan Marmara Gölünün kuruyor olması ülkemiz için önemli bir ekolojik problemdir. Bu duruma neden olabilecek pek çok sebep olabilir fakat sadece uydu görüntülerine bakılarak en net fark edilen şey göl civarındaki tarım alanlarının artması ve bölge de uygulanan yanlış tarımsal sulama uygulamalarıdır. $\mathrm{Bu}$ durumun önüne geçmek için tarımda doğru sulama yöntemleri kullanılmalıdır. Bunun daha detaylı olarak değerlendirilebilmesi için meteorolojiden alınacak kuraklık verileri, topografya verileri kullanılarak gölü besleyen suların önünü neyin kestiği gibi konular ilerleyen makalelerde araştırılacaktır. Ayrıca daha güncel uydu veri setleriyle çalışma güncellenecek ve daha detaylı sonuçlar elde edilebilecektir. Küresel ısınmayla birlikte Dünya genelinde tatlı su kayıpları sürmeye devam ederken ülkemize ait bu çok önemli su kaynağını korumak için acil eylem planları oluşturulması gereklidir.

\section{Bilgilendirme/Teşekkür}

Yazarlar, ücretsiz uydu verileri ve DSAS yazılımı için NASA'ya teşekkür eder.

\section{Araştırmacıların katkı oranı}

Abdurahman Yasin Yiğit: Literatür taraması, Makale yazımı; Halil İbrahim Şenol: Analizler, Makale yazımı; Yunus Kaya: Literatür taraması, Makale yazımı

\section{Çatışma beyanı}

Herhangi bir çıkar çatışması bulunmamaktadır.

\section{Kaynakça}

Ahmad SR \& Lakhan VC (2012). GIS-based analysis and modeling of coastline advance and retreat along the coast of Guyana. Marine Geodesy, 35(1), 1-15.
Ali I, Cawkwell F, Dwyer E, Barrett B \& Green S (2016). Satellite remote sensing of grasslands: from observation to management. Journal of Plant Ecology, 9(6), 649-671.

Ali PY \& Narayana AC (2015). Short-term morphological and shoreline changes at Trinkat Island, Andaman and Nicobar, India, after the 2004 Tsunami. Marine Geodesy 38(1), 26-39.

Armah FA (2011). GIS-based assessment of short term Shoreline changes in the coastal erosion-sensitive zone of Accra, Ghana. Research Journal of Environmental Sciences, 5(7), 643-54.

Beşel C \& Kayıkçı ET (2020). Investigation Of Black Sea Mean Sea Level Variability By Singular Spectrum Analysis. International Journal of Engineering and Geosciences, 5(1), 33-41.

Bevacqua A, Yu D \& Zhang Y (2018). Coastal vulnerability: Evolving concepts in understanding vulnerable people and places. Environmental Science \& Policy, 82, 19-29.

Boak EH \& Turner IL (2005). Shoreline definition and detection: A review. Journal of Coastal Research 21(4), 688-703.

Carr MH, Robinson SP, Wahle C, Davis G, Kroll S, Murray S, Schumacker EJ \& Williams M (2017). The central importance of ecological spatial connectivity to effective coastal marine protected areas and to meeting the challenges of climate change in the marine environment. Aquatic Conservation: Marine and Freshwater Ecosystems, 27, 6-29.

Ciritci D \& Turk T (2020). Assessment of the Kalman filter-based future shoreline prediction method. International Journal of Environmental Science and Technology, 17, 3801-3816.

Danforth WW \& Thieler ER (1992). Digital Shoreline Analysis System (DSAS) user's guide; version 1.0 (No. 92-355). US Geological Survey.

Das B \& Dhorde A (2015). Assessment of shoreline change and its relation with Mangrove vegetation: A case study over North Konkan region of Raigad, Maharashtra, India. International Journal of Engineering and Geosciences, 7(2), 101-111.

Dereli MA \& Tercan E (2020). Assessment of shoreline changes using historical satellite images and geospatial analysis along the Lake Salda in Turkey. Earth Science Informatics, 13(3), 709-718.

Dewidar KM \& Frihy OE (2010). Automated techniques for quantification of beach change rates using Landsat series along the North-eastern Nile Delta, Egypt. Journal of Oceanography and Marine Science, 1(2), 28-39.

Doygun H, Oğuz H, Atak BK \& Nurlu E (2011). Alan Kullanım Değişimlerinin Doğal Karakterli Kıyı Alanları Üzerindeki Etkilerinin Uzaktan Algılama ve CBS Yardımıyla İncelenmesi: Çiğli/İzmir Örneği, I. Akdeniz Orman ve Çevre Sempozyumu, Kahramanmaraş.

Döker MF (2012). İstanbul İli Marmara Denizi Kıyı Çizgisinde Meydana Gelen Zamansal Değişimin Belirlenmesi. International Journal of Human Scienses, 9(2),1250-1369.

Geyer WR, Hill PS \& Kineke GC (2004). The transport, transformation and dispersal of sediment by buoyant 
coastal flows. Continental Shelf Research, 24(7-8), 927-949.

Ghorai D \& Bhunia GS (2020). Automatic shoreline detection and its forecast: a case study on Dr. Abdul Kalam Island in the section of Bay of Bengal. Geocarto International, 1-20.

Glover C \& Robertson A (1998). Neotectonic intersection of the Aegean and Cyprus tectonic arcs: extensional and strike-slip faulting in the Isparta Angle, SW Turkey. Tectonophysics, 298(1-3), 103-132.

Gormsen E (1997). The impact of tourism on coastal areas. GeoJournal, 42(1), 39-54.

Gracy Margret Mary R, Sundar V \& Sannasiraj SA (2020). Analysis of shoreline change between inlets along the coast of Chennai, India. Marine Georesources \& Geotechnology, 1-10.

Guha S \& Govil H (2021). Relationship between land surface temperature and normalized difference water index on various land surfaces: A seasonal analysis. International Journal of Engineering and Geosciences, 6(3), 165-173.

Gül O (2008). Marmara Gölü (Manisa) kuş türleri populasyonlarının tespiti ve alanı etkileyen çevresel faktörlerin belirlenmesi üzerine araștırmalar [Researches on the determination of ornithofauna of and environmental factors affecting Marmara lake (Manisa, Turkey). Ege University, Institute of Science: M.Sc. Thesis

Hossain KT, Salauddin M \& Tanim IA (2016). Assessment of the dynamics of coastal island in Bangladesh using geospatial techniques: Domar Char. Journal of the Asiatic Society of Bangladesh, Science, 42(2), 219228.

İlhan A \& Sarı HM (2011): Marmara Gölü balık faunası ve balıkçlılk faaliyetleri. Ege Journal of Fisheries Aquatic Sciences, 30, 187-191.

Jana A, Maiti S \& Biswas A (2017). Appraisal of long-term shoreline oscillations from a part of coastal zones of Sundarban delta, Eastern India: A study based on geospatial technology. Spatial Information Research, 25(5), 713-723.

Kermani S, Boutiba M, Guendouz M, Guettouche MS \& Khelfani D (2016). Detection and analysis of shoreline changes using geospatial tools and automatic computation: Case of jijelian sandy coast (East Algeria). Ocean \& coastal management, 132, 46-58.

Kireeva M, Frolova N, Rets E, Samsonov T, Entin A, Kharlamov M, Telegina E \& Povalishnikova E (2020). Evaluating climate and water regime transformation in the European part of Russia using observation and reanalysis data for the 1945-2015 period. International Journal of River Basin Management, 18(4), 491-502.

Kurt S, Karaburun A, Demirci A (2010). Coastline Changes in İstanbul Between 1987 and 2007. Scientific Research and Essays 5(19), 3009-3017.

Mahmoodi A, Lashteh Neshaei MA, Mansouri A \& Shafai Bejestan M (2020). Study of current-and waveinduced sediment transport in the Nowshahr Port entrance channel by using numerical modeling and field measurements. Journal of Marine Science and Engineering, 8(4), 284.
Mitra SS, Santra A \& Mitra D (2013). Change detection analysis of the shoreline using Toposheet and Satellite Image: A case study of the coastal stretch of Mandarmani-Shankarpur, West Bengal, India. International Journal of Geomatics and Geosciences, $3(3), 425$.

Nassar K, Fath H, Mahmod WE, Masria A, Nadaoka K \& Negm A (2018). Automatic detection of shoreline change: case of North Sinai coast, Egypt. Journal of Coastal Conservation. https://doi.org/10.1007/s11852-018-0613-1.

Nassar K, Mahmod WE, Fath H, Masria A, Nadaoka K \& Negm A (2019). Shoreline change detection using DSAS technique: Case of North Sinai coast, Egypt. Marine Georesources \& Geotechnology, 37(1), 81-95.

Natesan U, Parthasarathy A, Vishnunath R, Kumar GEJ \& Ferrer VA (2015). Monitoring longterm shoreline changes along Tamil Nadu, India using geospatial techniques. Aquatic Procedia, 4, 325-332.

Niya AK, Alesheikh AA, Soltanpor M \& Kheirkhahzarkesh MM (2013). Shoreline change mapping using remote sensing and GIS. Int. J. Remote Sens. Appl., 3(3), 102107.

Nor NAM, Tahar KN, Suprijo T \& Sulaiman SAH (2020). Shoreline Changes Analysis Along the Coast of Kuala Terengganu, Malaysia using DSAS. In 2020 11th IEEE Control and System Graduate Research Colloquium (ICSGRC) (pp. 276-281).

Page SJ, Hartwell H, Johns N, Fyall A, Ladkin A \& Hemingway A. (2017). Case study: Wellness, tourism and small business development in a UK coastal resort: Public engagement in practice. Tourism Management, 60, 466-477.

Peel MC, Finlayson BL \& McMahon TA (2007): Updated world map of Köppen-Geiger climate classification. Hydrology and Earth System Sciences Discussions, 4, 1633-1644.

Phillips MR \& Jones AL (2006). Erosion and tourism infrastructure in the coastal zone: Problems, consequences and management. Tourism Management, 27(3), 517-524.

Rahman SA, Islam MM, Salman MA \& Rafiq MR (2022). Evaluating bank erosion and identifying possible anthropogenic causative factors of Kirtankhola River in Barishal, Bangladesh: an integrated GIS and Remote Sensing approaches. International Journal of Engineering and Geosciences, 7(2), 179-190.

Roy S \& Mahmood R (2016). Monitoring shoreline dynamics using landsat an d hydrological data: a case study of Sandwip Island of Bangladesh. The Pennsylvania Geographer, 54(2), 20-41.

Sebat M \& Salloum J (2018). Estimate the rate of shoreline change using the statistical analysis technique (Epr). Business \& It, 8(1).

Şentürk E \& Erener A (2017). Determination of temporary shelter areas in natural disasters by gis: A case study, Gölcük/Turkey. International Journal of Engineering and Geosciences, 2(3), 84-90.

Velsamy S, Balasubramaniyan G, Swaminathan B \& Kesavan D (2020). Multi-decadal shoreline change analysis in coast of Thiruchendur Taluk, Thoothukudi district, Tamil Nadu, India, using remote sensing and 
DSAS techniques. Arabian Journal of Geosciences, 13(17), 1-12.

Xoplaki E, Maheras P \& Luterbacher J (2001). Variability of climate in meridional Balkans during the periods
1675-1715 and 1780-1830 and its impact on human life. Climatic Change, 48(4), 581-615.

(c) (1)( ()

(C) Author(s) 2022. This work is distributed under https://creativecommons.org/licenses/by-sa/4.0/ 